\title{
The relation between pregnant adolescents' attitude about nutrition and weight gain during pregnancy and hemoglobin level"
}

\author{
Türkan Özünlü ${ }^{1}$, Senay Cetinkaya ${ }^{2 \#}$, \\ ${ }^{1}$ School of Health, University of Selçuk, Konya, Turkey \\ ${ }^{2}$ School of Health, University of Çukurova, Adana, Turkey \\ Email: " senayg_202@hotmail.com, scetinkaya@cu.edu.tr
}

Received 1 October 2012; revised 1 December 2012; accepted 9 December 2012

\begin{abstract}
Purpose: This study is carried out to analyze the relation of weight raise and hemoglobin level during pregnancy of pregnant adolescents to their nutriational attitudes. Methods: This study is a cross-sectional study carried out to examine the relationship between nutrition habits vs weight and level of hemoglobin in the 49 pregnant adolescents participants $(\leq 18$ years of age) who had applied to pregnant and emergency services in Şammas Vehbi Ekecik Gynecology and Children's Hospital in the city of Aksaray, Turkey, between February 15 and March 25, 2004, and accepted to participate in this study. General information regarding the pregnant adolescents, their knowledge on nutrition and nutritional habits were filled in during face-to-face interviews. These pregnant adolescents were monitored during the months of April, May, June and July and their measurements were taken. Data of the study were analyzed in a computer. Results: When the nutritional knowledge scores of the pregnant adolescents are considered, it was seen that $30(61.2 \%)$ had a good knowledge level, $10(20.4 \%)$ had a knowledge of intermediary level, and $9(18.3 \%)$ had a low or insufficient level of knowledge. As for the nutrition habit scores, 28 of pregnant adolescents $(57.1 \%)$ had fine, and 21 of them $(42.7 \%)$ had poor and inadequate levels of nutrition habits. Conclusion: When the relation between the hemoglobin levels measured of the pregnant adolescents' according to the their nutrition knowledge scores and the distribution of their habits was analysed, it was not found meaningful $(p>0.05)$.
\end{abstract}

Keywords: Adolescent Pregnancy; Nutrition; Hemoglobin; Weight; Nursing

\footnotetext{
${ }^{*}$ This study announced in Turkish Congress of Pediatry, March 15-20, 2006 as a verbal notice. This article was the post graduate thesis whose academic consultancy had been carried out by Senay Cetinkaya.

\#Corresponding author.
}

\section{INTRODUCTION}

Adolescence is a period of rapid growth and maturation between the ages of 12 and 20 in which important social and physical differences occur [1]. Another period in which physical, social and psychological differences occur is the pregnancy period. The consecutive experience of these periods puts the organism into risk. On this account, all the pregnant adolescents are considered as the risky group in medical sense [2,3]. 15 million babies, which is more than one tenth of the whole new-births in the world, are born from adolescent mothers [4]. In 2003, of the 421,241 preadolescent and adolescent US births, 84,570 were second or higher order births [5].

The growth of pregnant adolescents still goes on and has not yet reached complete physical maturity, and because of this, their need for nutrition is much more than adult females [6-8]. Premature birth, low birth weight, stillbirth and congenital disorders are mostly related to the insufficient and imbalanced nutrition of the mother during pregnancy $[9,10]$.

Hediger and his friends have shown that even if the required total of weight is gained till the end of pregnancy, the low birth weight risk increases if the required weight is not acquired till the 24th week, and they also found that insufficiency of weight gained in 1st and 2nd trimesters decreases the food stores of the mother and too much weight gain increases some food stores [11].

Anemia in pregnancy develops mostly because of nutrition deficient in iron and folic acid [1,12]. The most frequent anemia form that is experienced during pregnancy is iron deficiency anemia $[13,14]$. Another problem is the problem of energy consuming. According to this, adolescents are either overweight or too thin [14].

With the decreasing age of sexuality, the raise in the number of pregnant adolescents is a great problem for our country. It needs special care for both the problems that the adolescence period brings and for the dangers and needs that pregnancy causes. Adolescents' needs of 
independence and controlling their own life should be supported with the training by the nurse [15].

This study is carried out to analyze the relation of weight raise and hemoglobin level during pregnancy of pregnant adolescents to their nutritional attitudes.

\section{METHODS}

This study is a sectional one carried out with the aim of analyzing the relation of nutrition habits with weight and hemoglobin levels of 49 pregnant adolescents, who applied to the obstetrics and emergency services of Aksaray Şammas Vehbi Ekecik Gynecology and Obstetrics and Children's Hospital in the provincial center of Aksaray, Turkey, between February 15 and July 25 2004, and accepted to take participate in the study.

These pregnant adolescents were monitored during the months of April, May, June and July and their measurements were taken. Pregnant adolescents who completed the first trimester were included as samples in order to clearly monitor the weight increase. It's determined in the study by Abrams that the weight gain in the 2nd trimester is more related to the fetal development in comparison with the weight gain in the 1st and 3rd trimesters [16].

The general information questionnaire form related to nutrition knowledge, nutritional habits and general information on pregnant adolescents was prepared for the first consultation and filled in face to face by the researchers. With a verbal approval of pregnant adolescents, the form was filled without giving any training.

To collect data, the general information form on the pregnant women and general information on nutrition habits was used [17]. The questionnaire form consists of 35 questions. Six of these are about nutrition knowledge, 8 are about nutrition habits and the remaining 21 questions are about the socio-demographic features of the pregnant adolescents and their daily nutrition types.

Nutrition knowledge and habits are evaluated with the grading system which Arslan developed with the help of experts in the Department of Measurement and Evaluation of Hacettepe University [17]. Validity and reliability of this scale has been tested before. It was attempted top determine the nutrition knowledge of women at the start of the study. In order to find the nutrition knowledge of the pregnant women, each question was given a grade between 0 and 4 . Those with a knowledge level of 15 points or above out of 20 are considered to have a good level of knowledge and those with 14 points and below are considered as poor or inadequate.

Every question asked to determine the information on nutrition habits was given a grade between 0 and 6 . The highest grade in nutritional habits is 48 . As of the determination of information on nutrition habits, those with a score of 30 points and above are considered to have good habits, and those with a point of 29 and below are considered as bad or insufficient [17].

The hemoglobin levels of pregnant adolescents were evaluated in laboratories by obtaining verbal and written approval of chief doctor of Aksaray Şammas Vehbi Ekecik Gynecology and Obstetrics Children's Hospital. Measurements of hemoglobin levels are carried out between 10:00 and 11:00 in the morning. It was applied to every pregnant adolescents once per month during the four months of monitoring.

Hemoglobin levels lower than $11 \mathrm{~g} / \mathrm{dl}$ in the first and third trimesters and lower than $10.5 \mathrm{~g} / \mathrm{dl}$ in the second trimester is interpreted as anemia [1]. Iron deficiency anemia is common in healthy, iron-sufficient adolescent pregnant women during the second tirimester, and body stores of iron decline in both adolescent and adult pregnancies [18]. As of the hemoglobin levels of pregnant adolescents were checked during four months.

Weight measurements were performed using King brand EB 727 model precision digital scale. The weight of pregnant adolescents is measured four times with once per month. Weight measurements were performed with the same scale each time.

Study data are analyzed in computers. In the evaluation of data, percentage, average and standard deviation are used. In the comparison of groups, Chi-Square, Mann Whitney U, Wilcoxen tests are used. The level significance was taken as 0.05 .

\section{RESULTS}

\subsection{Socio-Demographic Characteristics of Pregnant Adolescents}

When the average age of the pregnant adolescents is considered, it is seen that $20(40.8 \%)$ of them is 18 years old, $25(51.0 \%)$ of them is 17 years old, and $4(8.2 \%)$ of them is 16 years old. The average age of pregnant adolescents is found to be $17.58 \pm 0.85$, and the average age of their husbands is $23.24 \pm 1.47$. When the education levels of pregnant adolescents and their husbands are examined, it was found that $15(30.6 \%)$ of the pregnant adolescents are high school graduates, 10 (20.4\%) of them are university students, $7(14.3 \%)$ of them are primary school graduates, $4(8.2 \%)$ of them are illiterate, and their husbands; $23(46.9 \%)$ of them are high school graduate, $18(36.7 \%)$ of them are university graduates, 5 $(10.2 \%)$ of them are elementary school graduates, 2 $(4.1 \%)$ of them are primary school graduate and $1(2 \%)$ of them is illiterate. When the family income levels of pregnant adolescents are examined, it is found $581.25 \pm$ 114.22 accordingly.

When we look at the occupations of pregnant adolescents, it is found that $38(77.6 \%)$ of them are housewives, 
$4(8.2 \%)$ of them are workers, $1(2 \%)$ of them is a civil servant, $6(12.2 \%)$ of them are of other occupational groups. When the pregnant adolescent's husbands' occupations are investigated, it is found that $4(8.2 \%)$ of them are unemployed, $26(53.1 \%)$ of them are workers, 9 $(18.4 \%)$ of them are civil servants and $10(20.4 \%)$ of them are of other occupational groups.

\subsection{Nutrition and Knowledge of Nutritional Habits in Pregnancy}

When the nutrition knowledge points of pregnant adolescents are checked, it is seen that $30(61.2 \%)$ of them have a high level, $10(20.4 \%)$ of them have a middle level, $9(18.3 \%)$ of them have an insufficient or low level of nutrition knowledge.

When the nutritional habit scores of pregnant adolescents included in the study are checked, it is seen that 28 $(57.1 \%)$ of them have a high level of nutrition knowledge, $21(42.7 \%)$ of them have an insufficient or low level of nutrition knowledge.

In the study, it is found that $26(53.1 \%)$ of the pregnant adolescents consume tea or coffee and $7(14.3 \%)$ of them smoked.

In this study, it is found that $43(87.8 \%)$ of the pregnant adolescents took preparations that contain iron, calcium or folic acid and $6(12.2 \%)$ of them didn't take such preparations. When the pregnant adolescents' consummation of calcium, iron or folic acid during pregnancy are examined, it is found that $3(6.1 \%)$ of them consumed these for 1 month, 21 (42.9\%) of them consumed these for 2 months, 14 (28.6\%) of them consumed these for 3 months, $5(10.2 \%)$ of them consumed these for 4 months, but $6(12.2 \%)$ of them didn't consume them. It is found that while 45 (91.8\%) of pregnant adolescents consumed milk, yoghurt and the sort during their pregnancy, $4(8.2 \%)$ of them never consumed milk, yoghurt and the sort.

The answers given to the question of "Which one makes blood?" by pregnant adolescents that are included in the study are as follows: $31(63.3 \%)$ of them said meat, liver and egg, 4 (8.2\%) of them said vegetable and fruit, $2(4.1 \%)$ of them said meat, liver, egg, potato and bread, $1(2.0 \%)$ said meat, liver, egg, sugar and fats, $11(22.0 \%)$ of them said meat, liver, egg, vegetable and fruit.

\subsection{Analysis of the Effect of Knowledge of Nutrition and Nutritional Habits on Increase of Weight and Hemoglobin Levels in Pregnancy}

When looked at the hemoglobin levels of the pregnant adolescents that are included in the study, it is seen that the average of hemoglobin level is $11.43 \pm 1.46 \mathrm{mg} / \mathrm{dl}$ during the first month (Table 1).
Table 1. Distribution of hemoglobin levels of pregnant adolescents.

\begin{tabular}{cc}
\hline & $\begin{array}{c}\text { Arithmetic Average } \pm \\
\text { Standard Deviation }\end{array}$ \\
\hline First Measurement (4th Month) & $11.43 \pm 1.46$ \\
Hemoglobin Level & $11.02 \pm 1.58$ \\
Second Measurement (5th Month) & \\
Hemoglobin Level & $11.11 \pm 1.57$ \\
Hemogrd Measurement (6th Month) & $11.04 \pm 1.42$ \\
\hline
\end{tabular}

When the hemoglobin levels of adolescence's that were obtained in the first months of monitoring is compared to their nutrition knowledge, it is found that pregnant women that with a low knowledge level and those with a high level of nutrition knowledge level had an average hemoglobin level, the difference is considered as statistically insignificant $(P>0.05)$. (respectively their average hemoglobin level $11.4 \pm 1.6 \mathrm{~g} / \mathrm{dl}$ and $11.3 \pm 1.3$ $\mathrm{g} / \mathrm{dl}$ ). When the pregnant adolescence's that with a low level and high level of nutritional habits are compared, the difference is considered as statistically insignificant $(\mathrm{P}>0.05)$ (respectively their average hemoglobin level $11.5 \pm 1.7 \mathrm{~g} / \mathrm{dl}$ and $11.3 \pm 1.3 \mathrm{~g} / \mathrm{dl}$ ) (Table 2).

When the adolescence's habits of attending to regular check up during pregnancy and their habits of getting drugs that contain calcium, iron or folic acid are compared, the difference was found to be statistically significant $\left(\chi^{2}=14,203, \mathrm{SD}=1, \mathrm{P}=0.00\right)(\mathrm{P}<0.05)$. When the habits of the adolescence's attending regular checkups and the periods of their having a blood test are compared, the difference was found to be statistically significant $\left(\chi^{2}=23.080, \mathrm{SD}=4, \mathrm{P}=0.00\right)(\mathrm{P}<0.05)$.

When the pre-pregnancy weight according to their own statements of pregnant adolescents who are included in the study and their weight in the first scaling month are compared, it is found that $16(32.7 \%)$ of them had gained $2.99 \mathrm{~kg}$ or less, $8(16.3 \%)$ of them had gained between $3-3.99 \mathrm{~kg}, 18(36.7 \%)$ of them had gained between 4 - 4.99, and $7(14.3 \%)$ of them had gained $5 \mathrm{~kg}$ and above.

The average of weight of pregnant adolescents in the first months is $53.13 \pm 4.50 \mathrm{~kg}$. As the result of 4 months of monitoring, their average of weight is found to be $65.30 \pm 5.42 \mathrm{~kg}$.

The distribution of weight gain of pregnant adolescents during the months of monitoring is seen in Table 3.

The analysis of the nutrition knowledge points and the 
Table 2. Examination of the hemoglobin levels measured of the pregnant adolescents' according to the their nutrition knowledge scores and the distribution of their habits.

\begin{tabular}{|c|c|c|c|c|c|}
\hline \multicolumn{6}{|c|}{ Distribution Nutrition Knowledge of Pregnant Adolescents } \\
\hline Hemoglobin Measurement Times of Pregnant adolescents & Good $(n=30)$ & Insufficient $(\mathrm{n}=19)$ & Mann-Whitney U & Wilcoxen Test & $\mathrm{P}>0.05$ \\
\hline 1st Measurement (4th Month) Level of Hemoglobin & $11.3 \pm 1.3$ & $11.4 \pm 1.6$ & 256.0 & 784.0 & 0.736 \\
\hline 2nd Measurement (5th Month) Level of Hemoglobin & $10.8 \pm 1.5$ & $11.1 \pm 1.7$ & 248.0 & 776.0 & 0.614 \\
\hline 3rd Measurement (6th Month) Level of Hemoglobin & $10.5 \pm 2.1$ & $11.3 \pm 1.8$ & 231.0 & 759.0 & 0.389 \\
\hline 4th Measurement (7th Month) Level of Hemoglobin & $10.9 \pm 1.3$ & $11.2 \pm 1.6$ & 242.0 & 770.0 & 0.528 \\
\hline \multicolumn{6}{|c|}{ Distribution of Nutritional Habits of Pregnant Adolescents } \\
\hline Hemoglobin Measurement Times of Pregnant adolescents & Good $(\mathrm{n}=28)$ & Insufficient $(\mathrm{n}=21)$ & Mann-Whitney U & Wilcoxen Test & $\mathrm{P}>0.05$ \\
\hline 1st Measurement (4th Month) Level of Hemoglobin & $11.3 \pm 1.3$ & $11.5 \pm 1.7$ & 237.0 & 832.0 & 0.696 \\
\hline 2nd Measurement (5th Month) Level of Hemoglobin & $10.8 \pm 1.4$ & $11.3 \pm 1.8$ & 213.0 & 808.0 & 0.362 \\
\hline 3rd Measurement (6th Month) Level of Hemoglobin & $10.5 \pm 2.1$ & $11.3 \pm 1.8$ & 218.5 & 813.5 & 0.428 \\
\hline 4th Measurement (7th Month) Level of Hemoglobin & $10.9 \pm 1.3$ & $11.2 \pm 1.6$ & 235.5 & 830.5 & 0.672 \\
\hline
\end{tabular}

Table 3. The distribution of weight gain of pregnant adolescents during the months of monitoring.

\begin{tabular}{ccc}
\hline Weight gain between 4th and 5th months & $\mathrm{n}$ & $\%$ \\
\hline $2.99 \mathrm{~kg}$ and below & 20 & 40.8 \\
$3-3.99 \mathrm{~kg}$ & 9 & 18.4 \\
$4-4.99 \mathrm{~kg}$ & 10 & 20.4 \\
$5 \mathrm{~kg}$ and above & 10 & 20.4 \\
\hline Weight gain between 5 th and 6th months & & \\
\hline $2.99 \mathrm{~kg}$ and below & 13 & 26.5 \\
$3-3.99 \mathrm{~kg}$ & 17 & 34.7 \\
$4-4.99 \mathrm{~kg}$ & 8 & 16.3 \\
$5 \mathrm{~kg}$ and above & 11 & 22.5 \\
\hline Weight gain between 6th and 7th months & & \\
\hline $2.99 \mathrm{~kg}$ and below & 4 & 8.2 \\
3 - 3.99 kg & 9 & 18.4 \\
$4-4.99 \mathrm{~kg}$ & 13 & 26.5 \\
$5 \mathrm{~kg}$ and above & 23 & 46.9 \\
Total & 49 & 100.0 \\
\hline
\end{tabular}

weight gains in followed months belong to adolescent pregnants is seen in Table 4.

When the weight level of pregnant adolescents measured in the first months of monitoring and their knowledge of nutrition were compared, it was found that the average of gained weight of pregnant adolescents that have insufficient nutrition habit score was $52.8 \pm 4.8 \mathrm{~kg}$ and that the average of gained weight of pregnant that have a good level nutrition habit was $53.2 \pm 4.2 \mathrm{~kg}$ (Table 5).

\section{DISCUSSION}

\subsection{Socio-Demographic Characteristics of Pregnant Adolescents}

Adolescence pregnancy is a public health problem that adversely affects mother and baby [8]. According Turkish Population and Health Survey in 2003, frequency of pregnancy between the ages of 15 and 19 is $7.5 \%$. The percentage of being a mother rises along with age in adolescence period. While this ratio is $1 \%$ at the age of 16 , it rises to $3 \%$ at the age of 17 , to $8 \%$ at the age of 18 and to $17 \%$ at the age of 19 [19]. When the average age of the pregnant adolescents is considered, it is seen that $20(40.8 \%)$ of them is 18 years old, $25(51.0 \%)$ of them is 17 years old, and $4(8.2 \%)$ of them is 16 years old. The average age of pregnant adolescents is found to be 17.58 \pm 0.85 .

One of the factors that raise possible risks in adolescent pregnancy is the fact that the adolescents are of a lower socio-economic group [1,20]. When the family income levels of pregnant adolescents are examined, it is found $581.25 \pm 114.22$ accordingly.

\subsection{Nutrition and Knowledge of Nutritional Habits in Pregnancy}

In the study, it is found that $26(53.1 \%)$ of the pregnant adolescents consume tea or coffee and $7(14.3 \%)$ of them smoked. This diagnosis shows the need of giving education to the pregnants about these subjects from the health workers. 
Table 4. Analysis of nutrition knowledge scores of pregnant adolescents and their weight gain during the months of monitoring.

\begin{tabular}{lrrrrr}
\hline \multicolumn{5}{c}{ Distribution of Nutrition Knowledge in Pregnant Adolescents } \\
\hline Weight Measurement Times of Pregnant Adolescents & Good (n=30) & Insufficient (n=19) & Mann-Whitney U & Wilcoxen Test & P >0.05 \\
\hline Weight Gained in the 1st Measurement (4th Month) & $53.5 \pm 4.2 \mathrm{~kg}$. & $52.4 \pm 4.7 \mathrm{~kg}$. & 220.0 & 373.0 & 0.271 \\
Weight Gained in the 2nd Measurement (5th Month) & $56.6 \pm 4.0 \mathrm{~kg}$. & $56.2 \pm 4.9 \mathrm{~kg}$. & 251.0 & 404.0 & 0.657 \\
Weight Gained in the 3rd Measurement (6th Month) & $60.2 \pm 4.7 \mathrm{~kg}$. & $60.0 \pm 5.3 \mathrm{~kg}$. & 269.5 & 422.5 & 0.958 \\
Weight Gained in the 4th Measurement (7th Month) & $64.8 \pm 5.0 \mathrm{~kg}$. & $65.1 \pm 5.7 \mathrm{~kg}$. & 269.5 & 797.5 & 0.958 \\
\hline
\end{tabular}

Table 5. Analysis of nutritional habit scores of pregnant adolescents and their weight gain during the months of monitoring.

\begin{tabular}{lccccc}
\hline \multicolumn{5}{c}{ Distribution of Nutritional Habits of Pregnant adolescents } \\
\hline Weight Measurement Times of Pregnant Adolescents & Good (n=28) & Insufficient (n=21) & Mann-Whitney U & Wilcoxen test & P >0.05 \\
\hline Weight Gained in the 1st Measurement (4th Month) & $53.2 \pm 4.2 \mathrm{~kg}$. & $52.8 \pm 4.8 \mathrm{~kg}$. & 231.5 & 351.5 & 0.608 \\
Weight Gained in the 2nd Measurement (5th Month) & $56.4 \pm 3.9 \mathrm{~kg}$. & $56.5 \pm 5.2 \mathrm{~kg}$. & 244.5 & 364.5 & 0.818 \\
Weight Gained in the 3rd Measurement (6th Month) & $60.0 \pm 4.6 \mathrm{~kg}$. & $60.3 \pm 5.6 \mathrm{~kg}$. & 250.0 & 845.0 & 0.913 \\
Weight Gained in the 4th Measurement (7th Month) & $64.6 \pm 4.9 \mathrm{~kg}$. & $65.6 \pm 6.0 \mathrm{~kg}$. & 236.0 & 831.0 & 0.679 \\
\hline
\end{tabular}

After the second half of pregnancy, additional external iron preparations must be consumed by all means. The iron is related to the blood amount of not only of the baby, but also of the mother as well, due to the increased blood amount by $30 \%$. It has been shown in a study that iron absorption increases with the gestational age [10]. It has been found as $7 \%$ in the 12 th week, $36 \%$ in the 24 th week and $66 \%$ in the 36 th week. If sufficient iron is not consumed, the baby may absorb iron stocks of mother and the mother may develop anemia and weakness [21].

In this study, it is found that $43(87.8 \%)$ of the pregnant adolescents took preparations that contain iron, calcium or folic acid and $6(12.2 \%)$ of them didn't take such preparations.

In addition to routine screening tests, regular full blood counts may need be taken, as teenage women are more likely to develop anaemia during their pregnancy [22].

When the habits of the adolescence's attending regular check-ups and the periods of their having a blood test are compared, the difference was found to be statistically significant $\left(\chi^{2}=23.080, \mathrm{SD}=4, \mathrm{P}=0.00\right)(\mathrm{P}<0.05)$.

In a study carried out by Siega in 2002, the pregnant women in North Carolina were examined, and it was found that the iron intake recommended with diet is met only in $30 \%$ of pregnant women, and the consumption of folate is met only in $60 \%$ of pregnant women [23]. This shows that American women even with high levels of income do not take their nutritional requirements only through their diet, and the need of supplements of multivitamins for an important pregnant population. However, in the compliance studies carried out, it was found that about one-thirds of pregnant women do not take the pre- scribed multivitamins. It is also found out that the women that have a lower level of education and that are younger consume less multivitamins [24]. In this study, it is found that it must be questioned whether or not the pregnants come for clinical check-ups regularly and use iron, calcium and folic acids.

The US Centers for Disease Control and Prevention (CDC) recommends starting iron supplementation in the twelth week of pregnancy or at the first prenatal visit. Supplements of $15-30 \mathrm{mg}$ of iron are adequate for most women during pregnancy [25].

\subsection{Analysis of the Effect of Knowledge of Nutrition and Nutritional Habits on Increase of Weight and Hemoglobin Levels in Pregnancy}

In Turkey, nearly half of the non-pregnant women and nearly two thirds of pregnant women have anemia caused by iron deficiency. Again in Turkey, it is found that $73.9 \%$ of pregnant women are anemic and that $16.1 \%$ of this is at a serious ( $\mathrm{Hb} 7.9$ and $\downarrow \mathrm{g} / \mathrm{dl}$ ) level, $35.1 \%$ is at a intermediary $(\mathrm{Hb} 8-9.9 \mathrm{~g} / \mathrm{dl})$ level and $22.7 \%$ is at a low level (Hb 10 - $10.5 \mathrm{~g} / \mathrm{dl})$ [26].

When looked at the hemoglobin levels of the pregnant adolescents that are included in the study, it is seen that the average of hemoglobin level is $11.43 \pm 1.46 \mathrm{mg} / \mathrm{dl}$ during the first month (Table 1).

When the average of fourth (7th month) hemoglobin measurement level, that is, the last hemoglobin measurement levels and the level of their nutritional habits were compared, it was found that pregnant women with 
insufficient nutrition knowledge scores had an average level of hemoglobin about $11.2 \pm 1.6 \mathrm{~g} / \mathrm{dl}$, and that pregnant adolescents with a high level of nutrition knowledge score had an average level of hemoglobin about $10.9 \pm$ $1.3 \mathrm{~g} / \mathrm{dl}$ (Table 2).

Whittaker and colleagues examined the absorption of iron by adding ascorbic acid and in the 12th week of pregnancy, and reported the level of absorption as \% 7.6, $21.1 \%$ in the 24 th week, and $37.4 \%$ in the 36 th week. In this way, the increasing need for iron can be provided with necessary additions [27].

The recommended daily energy increase of $300 \mathrm{kcal}$ is $17 \%$ of the pre-pregnancy need, but the need for vitamin and minerals increases at the amount of $20 \%$ to $100 \%$. On this account, the aim when choosing foods should be directed at consuming high-density foods that can provide not only the energy deficit, but also the increased vitamin and mineral need (for example a high nutrient density food like milk should be preferred to a low nutrient density food like fried potatoes). But this shouldn't be perceived as a need to get vitamin and mineral preparations during pregnancy [28].

Consequently, even when the pregnant women are given multivitamin supplements, it must be clearly stated that multivitamin preparations do not provide the entire portion of the necessary nutrients, but just a small portion of it, and it cannot replace a healthy diet. The pregnant women should be made aware about varied and balanced nutrition and their habits of nutrition should be assessed. All the nutrients for which the need raises during pregnancy can be provided (unless the pregnant has a nutritional risk factor) with the awareness raised about balanced nutrition via diets except iron and folate [29].

In non-pregnant adolescents the weight increase is 3 $\mathrm{kg}$ per year. Hence, for weight gained during pregnancy, it is accepted that the adolescences need to put on more weight because of growth [30].

When the pre-pregnancy weight according to their own statements of pregnant adolescents who are included in the study and their weight in the first scaling month are compared, it is found that $16(32.7 \%)$ of them had gained $2.99 \mathrm{~kg}$ or less, $8(16.3 \%)$ of them had gained between $3-3.99 \mathrm{~kg}, 18$ (36.7\%) of them had gained between $4-4.99$, and 7 (14.3\%) of them had gained $5 \mathrm{~kg}$ and above.

When the weight gained by pregnant adolescents included in the study between the first and last measurement is considered, it is found that $7(14.3 \%)$ of them has gained 7 - $8.99 \mathrm{~kg}, 7(14.3 \%)$ of them had gained 9 $10.99 \mathrm{~kg}, 16(32.7 \%)$ of them had gained $11-12.99 \mathrm{~kg}$, $10(20.4 \%)$ of them had gained $13-14.99 \mathrm{~kg}, 9(18.3 \%)$ of them had gained $15 \mathrm{~kg}$ and above.

The average of weight of pregnant adolescents was $53.13 \pm 4.50 \mathrm{~kg}$ in the first months of monitoring. The average weight after 4 months of observation was found to be $65.30 \pm 5.42 \mathrm{~kg}$.

When the weight of pregnant adolescents' included in the study gained between 4th and 5th months of pregnancy was considered, it was found out that 20 (40.8\%) of them had gained $2.99 \mathrm{~kg}$ or less, $9(18.4 \%)$ of them had gained $3-3.99 \mathrm{~kg}, 10(20.4 \%)$ of them had gained 4 - $4.99 \mathrm{~kg}$ and $10(20.4 \%)$ of them had gained $5 \mathrm{~kg}$ or more (Table 3).

When the weight level of pregnant adolescents during the first months of monitoring and their knowledge of nutrition was examined, it was found that the average of weight level of pregnant adolescents with insufficient nutrition knowledge score is $52.4 \pm 4.7 \mathrm{~kg}$, and that the average of weight level of pregnant adolescents with a good nutrition knowledge score was $53.5 \pm 4.2 \mathrm{~kg}$ (Table 4).

When the weight level of pregnant adolescents measured in the first months of monitoring and their knowledge of nutrition were compared, it was found that the average of gained weight of pregnant adolescents that have insufficient nutrition habit score was $52.8 \pm 4.8 \mathrm{~kg}$ and that the average of gained weight of pregnant that have a good level nutrition habit was $53.2 \pm 4.2 \mathrm{~kg}$ (Table 5).

When gained weight of pregnant are considered, it is seen that there was not much difference between months and that weight gain of those who have a good score of nutrition knowledge and habit is lower than the ones that have an insufficient score of nutrition knowledge and habit. Also the pregnant adolescents included in the study with insufficient or intermediate score of nutrition knowledge and habit had a higher level of hemoglobin compared to those with a good score. In other words, because those with a low score of nutrition are not nourished adequately, they consume more food, thus their level of hemoglobin increase along together with their weight. However, those with a good score of nutrition are careful about the way of nourishment, and thus their levels of hemoglobin and weight remain in a lower level. The conclusion from this is the need to give food rich in iron as training. Also, this finding is notable for it indicates that a separate training program is needed for pregnant adolescents.

Because intrauterine nutrition of babies of the pregnant women with a lower weight than the required weight will not be sufficient, inadequate weight gain during pregnancy may cause low birth weight as compared to other babies [25,31]. It is reported that at least 4 more kilograms more weight should be gained during the pregnancy than the suggested weight gaining of $11-12 \mathrm{~kg}$ for giving births to babies of the similar birth-weight, in comparison with the adult females [32].

Fernandez et al. suggest that adolescent prepregnancy 
weight categories be assessed using the CDC BMT charts and to examine gestational weight gain distributions exclusively among adolescent according to the CDC BMI categories [33]. Creation of gestational weight gain recommendations based on the Centers for Disease Control and Prevention body mass index percentiles would potentially assist clinicians in counseling adolescents regarding gestational weight gain [34]. Most adolescent and adult women will only require an additional 100 350 calories in the first twenty-two weeks of pregnancy. Weight gain rates of less than 0.5 pounds per week in the second half of pregnancy or less than 0.75 pounds per week in the third trimester dramatically increase the risk of having a preterm or small-for-gestational-age infant [25].

In a literature review performed by Abrams et al. in 2000 , women gaining weight within the limits recommended by IOM (Institute of Medicine) had the best results as regards maternal and fetal outcomes (low birth weight, macrosomy, spontaneous preterm birth rates, caesarian section, maternal postpartum obesity). However, it was reported that only $30 \%-40 \%$ of the women were able to gain weight within the recommended limits [28].

The nursing career requires not only treatment and care of the inpatients, but also the training and consulting services in matters with priority in society such as health of adolescent, woman, child and old people. When the period of adolescence merges with the period of pregnancy, a new period risky for both the adolescence and the new-born emerges. In order to provide the necessary nursing treatment in this period, nurses in sufficient number and of a certain quality are needed. By this way, pregnant adolescents can be provided with regular checkups and one to one education and consulting [15].

\section{CONCLUSIONS}

Adolescent pregnancy has gained an elevated awareness within the public as a result of the decreasing age of sexuality and increasing chance of miscarriage and other delivery problems. Perhaps owing to this, there is a better chance of discussing "healthcare personnel's training programs" and similar measures to prevent further damage and potential healthcare risks.

The nature of this study consisted of limited number of samples (although sufficiently large for this study) chosen in a limited time (Feb. 15-Mar. 25) and living on a limited area. Any conclusion we could possibly derive from this study can only bear a torch to the future studies in this field, and most favorably, those to be made in the same region. Nevertheless, this doesn't mean we wouldn't extract or suggest any practical implications in the end; so we have some.
Knowledge is still gold; it helps you to assess the situation you are into. Awareness in what you have, what you eat and what you spend will maximize the benefits even where the environmental factors, such as agricultural or socio-economical favors did not exist. Without knowledge and determination, habits cannot be reshaped, bad ones cannot be abandoned.

To draw a generalized and valid conclusion here, pregnant adolescents should be given "iron-rich" diets with "nutrient-dense" foods. Furthermore, particular training courses should be arranged about dietary prohibitions, their body needs and nutrition behaviors and related metabolic readings should be monitored as thoroughly as possible. Any supplementary mineral intakes or staff's direct interference to patient behavior may be of a future conduct to be decided anytime in this period.

The nursing career requires not only the treatment and care of ordinary patients, but also the training and consulting services regarding to some of the most prominent healthcare topics in our society that involves adolescents, women, children and old people. When the period of adolescence merges with pregnancy, a new period risky for both lives comes to existence. To provide with the necessary treatment and nursing, healthcare personnel should be in sufficient numbers, adequately educated and very-well trained to catch up the service quality standards needed. Only by this way, pregnant adolescents can be given regular check-ups, one-to-one education and counseling sessions.

\section{REFERENCES}

[1] Taşkın, L. (1998) Pregnancy and maternal age, birth and women's health nursing. 3rth Edition, System Printings.

[2] Saralioğlu, F., Yurdakök, M., Kutluk, M. and Çalıkoğlu, A. (1993) Diagnosis and treatment of childhood diseases. Güneş Publishing, Ankara, 263-275.

[3] Tüzün, N., Tinaz, M. and Elbi, A. (1995) Healthy living. Özbaşkan Publishing, 464-492.

[4] Başer, M. (2000) Adolescent sexuality and pregnancy. C. Ü. Nursing High School Publish, 50-55.

[5] Raneri, L.G. and Wiemann, C.M. (2007) Social ecological predictors of repeat adolescent pregnancy. Perspectives on Sexual and Reproductive Health, 39, 39-47. doi: $10.1363 / 3903907$

[6] Grant, J. (1986) The status of the world's children. UNICEF.

[7] Najjan, M.F. (1987) Anthropometric reference data and prevelance of owerweight. Vital and Health Statistics Series, 11, 238.

[8] Özünlü, T. and Çetinkaya, Ş. (2008) The nutritions and nutrition problems of the pregnancies of the adolescence. Turkiye Klinikleri Journal of Pediatrics, 17, 27-36.

[9] Atilla, B. and Bozkurt, N. (1984) The nutritional status of 
pregnant women and the relationship between hemoglobin levels and baby's birth weight. Journal of Nutrition and Diet, 13, 7-20.

[10] Ata, M.B. (2001) Secrets of gynecology and obstetrics. Bezmi Alem Valide Sultan Faundation Gureba Hospital Women Treatment and Birth Clinic, 164-169.

[11] Hediger, M.L., School, T.O. and Belky, D.I. (1989) Pattern of weight gain in adolescent pregnanc effect on birth weight and preterm delivery. Obstetrics \& Gynecology, 74, 6-12.

[12] Api, O., Ünal, O. and Şen, C. (2005) Pregnancy nutrition, weight gain and exercise. Journal of Perinatology, 13, 71-79.

[13] Alper, M., Selçukbiricik, S. and Elmar, P.S. (1999) Anemia in pregnancy. Obstetric and Gynecology, 118-122.

[14] Skinner, J.D. and Carruth, B.R. (1991) Dietary quality of pregnant and not-pregnant adolescent. Journal of the American Dietetic Association, 91, 718-720.

[15] Çavuşoğlu, H. (2000) Adolescent pregnancy, infant and child mortality rates by demographic characteristics. Childcare Nursing, 5, 62-63.

[16] Institute of Medicine (1990) Nutrition during pregnancy, weight gain and nutrient supplements. Report of the Subcommittee on Nutritional Status and Weight Gain during Pregnancy, Subcommitee on Dietary Intake and Nutrient Supplements during Pregnancy, Committee on $\mathrm{Nu}-$ tritional Status during Pregnancy and Lactation, Food and Nutrition Board, National Academy Press, Washington DC.

[17] Arslan, P., Karaağaoğlu, N., et al. (1993) Nutrition habits of young people in higher education by the method of grading. Journal of Nutrition and Diet, 22, 195-208.

[18] Meier, P.R., Nickerson, H.J., Olson, K.A., Berg, R.L. and Meyer, J.A. (2003) Prevention of iron deficiency anemia in adolescent adolescent and adult pregnancies. Clinical Medicine \& Research, 1, 29-36. doi:10.3121/cmr.1.1.29

[19] Türkiye Nüfus Sağlık Araştırmaları TNSA (2003) Hacettepe Üniversitesi Nüfus Etüdleri Enstitüsü, Ankara.

[20] Gökçe, B., Özşahin, A. and Zencir, M. (2007) Determinants of adolescent pregnancy in an urban area in Turkey: A population-based case-control study. Journal of Biosocial Science, 39, 301-311. doi:10.1017/S0021932006001763

[21] Chang, S.C. (2003) Hemoglobin levels affect outcomes in pregnant African-American adolescent. John Hopkins Bloomberg School Public Health.

[22] Myers, J.E., Heazell, A.E., Jones, R.L. and Baker, P.N. (2006) Obstetric management of teenage pregnancy. Fetal and Maternal Medicine Review, 17, 317-325. doi:10.1017/S0965539506001847
[23] Siega, R., Bodnar, L.M. and Savitz, D. (2002) What are pregnant women eating? Nutrient and food group diffences by race. Obstetrics \& Gynecology, 186, 480-486. doi: $10.1067 / \mathrm{mob} .2002 .121078$

[24] Rooney, B.L. and Schauberger, C.W. (2002) Excess pregnancy weight gain and long term obesity: one decade later. Obstetrics \& Gynecology, 100, 245-252. doi:10.1016/S0029-7844(02)02125-7

[25] Stang, J., Story, M. and Feldman, S. (2005) Nutrition in adolescent pregnancy. International Journal of Childbirth Education, 20, 4-11.

[26] Sağlık, T.C. and Bakanlığı, H.Ü. (1993) Nüfus Etütleri Enstitüsü ve Macro International I, Turkey Demographic and Health Survey, Ankara.

[27] Whittaker, P.G., et al. (1991) Iron absorption during normal human pregnancy: A study using stable isotopes. British Journal of Nutrition, 65, 457-463. doi:10.1079/BJN19910104

[28] Abrams, B., Altman, S.L. and Pickett, K.E. (2000) Pregnancy weight gain: Still controversial. The American Journal of Clinical Nutrition, 71, 1233-1241.

[29] Jovanovic, L. (2000) Medical nutritional therapy in pregnant women with pregestational diabetes mellitus. Journal of Maternal-Fetal Medicine, 9, 21-28. doi:10.1002/(SICI)1520-6661(200001/02)9:1<21::AIDMFM6>3.0.CO;2-P

[30] Haick, L. and Lederman, S.A. (1988) The relationship between maternal weight for height and term birth weight it teens and adult women. Journal of Adolescent Health Care, 10, 16-22. doi:10.1016/0197-0070(89)90041-7

[31] Greatsas, G. and Elsheikh, A. (1998) Adolescent pregnancy and results, 2. Science of Birth and Gynecology Department, Atina University, Aretaieion Hospital, Atina.

[32] School, T.O., Hediger, M.L., Ances, I.G., et al. (1988) Weight gain during adolescent pregnancy: Associated maternal characteristics and effects on-birth weight. Journal of Adolescent Health Care, 9, 286-290. doi:10.1016/0197-0070(88)90251-3

[33] Fernandez, I.D., Olson, C.M. and Dye, T.D.V. (2008) Discordance in the assessment of prepregnancy weight status of adolescents: A comparison between the centers for disease control and prevention sex-and age-specific body mass index classification and the Institute of Medicine-based classification used for maternal weight gain guidelines. Journal of the American Dietetic Association, 108, 998. doi:10.1016/j.jada.2008.03.012

[34] Groth, S. (2007) Are the Institute of Medicine recommendations for gestational weight gain appropriate for adolescent? Journal of Obstetric, Gynecologic, and Neonatal Nursing, 36, 21-27. doi:10.1111/j.1552-6909.2006.00117.x 